\title{
Al Adoption in the Printing Industry: A FVM perspective
}

\section{Muhammad Yusuf Masod, Siti Farhana Zakaria, Ruslan Abdul Rahim}

Faculty of Art \& Design, Universiti Teknologi MARA (UiTM) Kampus Puncak Alam, Bandar Puncak Alam 42300, Malaysia

yusuf595@uitm.edu.my, farha981@uitm.edu.my, ruslan@uitm.edu.my

Tel of 1st Author: +60123888201

\begin{abstract}
Despite its application in high-profile areas, Al's utilisation in the print manufacturing sector is still scarce. Competitiveness and advances in this sector urgently require higher value-added processes, including digitisation, incorporation of advanced manufacturing technologies, and efficient resource utilisation. This paper outlined challenges in organisational adoption of Al demands systematic assessment of the fit and viability of software implementations in heterogeneous, concurrent, and integrated systems while accounting for the performance, efficiency, stability, and sustainability of the sector. We develop a working framework for further assessment based on multiple theories and case studies, with particular attention to the FitViability Model (FVM).
\end{abstract}

Keywords: Al technologies adoption and implementation; Fit-Viability Model; printing industry; Industry 4.0

eISSN: 2398-4287@ 2021. The Authors. Published for AMER ABRA cE-Bs by e-International Publishing House, Ltd., UK. This is an open access article under the CC BYNC-ND license (http://creativecommons.org/licenses/by-nc-nd/4.0/). Peer-review under responsibility of AMER (Association of Malaysian Environment-Behaviour Researchers), ABRA (Association of Behavioural Researchers on Asians/Africans/Arabians) and cE-Bs (Centre for Environment-Behaviour Studies), Faculty of Architecture, Planning \& Surveying, Universiti Teknologi MARA, Malaysia.

DOI: https://doi.org/10.21834/ebpj.v6iSI5.2945

\subsection{Introduction}

Malaysia's manufacturing sector is moving towards a higher value-added process, with digitisation, advanced manufacturing technologies, and efficient resource utilisation. All this is meant to ensure the manufacturing sector remains relevant and competitive both locally and globally. To support this transformation, the Ministry of International Trade and Industry, introduced the National Policy on Industry 4.0, also known as Industry 4WRD, on October 31, 2018.

Artificial intelligence, among other innovations, has been recognized as the enabling technology for Industry 4.0. From its initial development 69 years ago to its latest breakthroughs in machine learning, Al offers solutions that are becoming crucial tools in organisational management assistance, especially as regards improvements in decision-making processes. Therefore, Al solutions are expected to bring a new dimension to the industrial environment, resulting in a dramatic increase in industrial productivity.

This evolution looks to include the rapidly changing global print manufacturing landscape, which sees growing calls for printing firms to re-evaluate their current approaches and strategies to remain relevant and competitive. Currently, the Malaysian printing industry is operating in survival mode due to its participants' inability to invest large sums in importing the latest, and thereby expensive machinery, leaving small firms unable to compete against the giants (Willy, 2018). The subsequent inequality in resources significantly impacts the industry as a whole, as witnessed by the reduction in the number of small-scale printing firms that cannot compete with the larger firms that can cost-effectively and quickly print the same products with better quality. To address this situation, smaller firms need to make better use of information technology (IT) as a tool to compete in the challenging printing market. IT can be used for various purposes, whether they are innovations in printing methods or management of day-to-day operations (Masod, 2018; Melnikov \& Semenyuk, 2014 Kipphan, 2001).

eISSN: 2398-4287@ 2021. The Authors. Published for AMER ABRA cE-Bs by e-International Publishing House, Ltd., UK. This is an open access article under the CC BYNC-ND license (http://creativecommons.org/licenses/by-nc-nd/4.0/). Peer-review under responsibility of AMER (Association of Malaysian Environment-Behaviour Researchers), ABRA (Association of Behavioural Researchers on Asians/Africans/Arabians) and cE-Bs (Centre for Environment-Behaviour Studies), Faculty of Architecture, Planning \& Surveying, Universiti Teknologi MARA, Malaysia.

DOI: https://doi.org/10.21834/ebpj.v6iSl5.2945 


\subsection{Literature Review}

Previously published studies on the effects of technology and pricing in the printing industry (Hultén et al., 2009) identified certain benefits associated with an investment in the new printing technology, namely competitive advantage and pricing. The findings indicate that among the benefits of new printing technologies is the possibility of changing consumer prices when newly available services reduce delivery time and costs and reflect substantial differences between the new services and available substitutes. One major drawback of the Hultén study is that it lacks a comprehensive analysis of the internal and external forces influencing the implementation of Al, as well as the complexity of the printing processes involved in the industry. These would require a much more systematic approach to identifying how technological, organisational, and environmental factors interact with other variables that are believed to be linked to productivity.

With these limitations in mind, this paper follows several paths in its research approach. We begin with a closer look at the various Industry 4.0 technologies involved, include Al, embedded intelligence, and the Internet of Things (loT) (Schwab, 2016). What we have found was that the desired boom in the digital transformation of ES could come by way of bridging the technologies with the software. $A$ recent study reveals that $E S$, on being infused with $\mathrm{Al}$, acquire machine learning and cognitive technologies, which, in turn, automate the ES to perform tasks that would normally require human intelligence (Masod, 2018; Li, Hou, Yu, Lu, \& Yang, 2017 Bodrow, 2017; Reiner, 2014). These breakthrough solutions should reflect their operational performance, usage load, and environment to enhance their performances, lifetimes, and quality, thereby ensuring unlimited customer satisfaction. A further benefit of Al is its ability to empower ES to gather data on their own through powerful analytics and predictive capabilities; moreover, it will be able to translate this data collection into cost savings, innovation and profitability. Complementing the already automated system with loT technology should further automate the very business processes governed by the ES. However, the study's main weakness is its failure to address how this technology can be integrated into the highly complex printing industry sector.

All the studies reviewed so far(Soja and Paliwoda-Pękosz, (2009), Skobelev, (2018), Ding and Qu, (2014), . Awa et al., (2016), Xu et al., (2017)) however, suffer from the same deficiency: they lack the characteristics of task (the nature of business processes in print manufacturing) and technology, as well as the dimension of viability. The research would have been more relevant if these aspects were included. These findings provide a basis for this study, since the most significant features of Al solutions are functionality and productivity, namely the ability to improve the functionality and productivity of an organization. To date, Al has been applied to highprofile areas, and most applications focus on autonomous guidance systems rather than production management. Although there is a general notion that Al solutions could be applied to benefit the printing industry, full utilisation is still scarce in this industry (Karlovits, 2017; Roos, 2016; Yang et al., 2010; Baray et al., 2008), and very little exploration has been conducted regarding how to enhance business processes, the implications of Al technology, or the critical factors that could affect the success or failure of Al applications.

This paper thus aims to fill this gap by answering the following research questions:

1. What theoretical framework can be used in studying the printing industry's adoption of artificial intelligence solutions in Malaysia?

2. What are the identifying factors that may affect the adoption of Al solutions in the printing industry?

With these stated research questions in mind, the further purpose of this study is to discuss and identify the significant factors that specifically affect the adoption of Al solutions in the Malaysian printing industry by extending the conceptual model and proposing practical instruments to assess Al solutions adoption.

\subsection{Al's impact on the printing industry}

The integration of Al and print manufacturing integration has also been shown to increase both production and economic efficiencies by compensating for labour shortages, increasing production flexibility, and achieving low cost. Moreover, by introducing complex systems engineering, other benefits of this integration may include mass customization, more accurate market forecasting through matching supply and demand, the promotion of a manufacturing service transformation, and improvements in quality control, all of which may serve as effective solutions for common problems and challenges that all countries in the world face, such as Al standardization, information security, and the fostering and implementation of talent. On a practical level, this integration can translate into intelligent products and facilities, smart plants, intelligent management services, intelligent supply chain management, intelligent monitoring and decision making (Li, Hou, Yu, Lu, \& Yang, 2017; Naser, 2018; Renzi, Leali, Cavazzuti, \& Andrisano, 2014), as well other benefits as illustrated in figure 1.

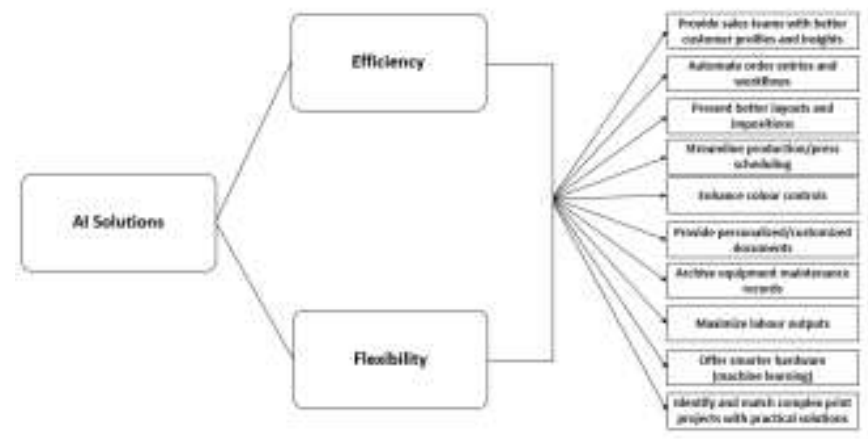

Fig. 1: The characteristics and economic value of Al solution 
As discussed above, the practicality of implementing Al solutions is somewhat questionable, despite their theoretically being aptly applied to most of the activities in production management. Therefore, before an organisation adopts this technology, it is imperative that it looks into the many factors involved, above and beyond the needs of such tools. In other words, for an organisation to achieve smart manufacturing, we propose a more comprehensive research model that includes those factors most relevant to the organisation. These types of research models have been proven useful in analysing organisational adoptions of electronic commerce initiatives and of mobile technologies (Tjan, 2001; Liang et al., 2007).

\subsection{The Fit-Viability Model}

A seminal work by Tjan, (2001), used to evaluate e-commerce adoption among organisations, proposed the fit-viability model, which considers two dimensions in evaluating internet initiatives: fit and viability. The former examines the extent to which new network applications are consistent with a firm's needs, core competency, structure, values, and organisational culture. In the equally important viability dimension, the model evaluates the extent to which new e-commerce applications can add value. It can also examine the requirements of human resources and capital. Together, these two dimensions form a simple matrix with the fit as the horizontal axis and viability as the vertical axis. Liang, Huang, Yeh, \& Lin, (2007b) used this model in their research on the adoption of mobile commerce technologies to understand its determinants. The resulting diagnostic tool was then utilised by O'Donnell \& Jackson, (2007) in their case studies to analyse key success criteria in mobile commerce in Australia. The extent to which the feature of a particular technology matches the needs of the task it is intended for was examined in a separate, revised version of this model; Liang et al. (2007) revised this model by incorporating the TTF model, which only considers the match between the task and technology, excluding the individual factors (seen as part of the organizational viability). Moreover, the revised model examined the extent to which the infrastructure of an organisation is ready to adopt new technologies from the perspective of the viability dimension. Overall, the revised model allows prospective adopters to consider the economic feasibility, technical infrastructure, and social readiness of their organisation before committing to the technology.

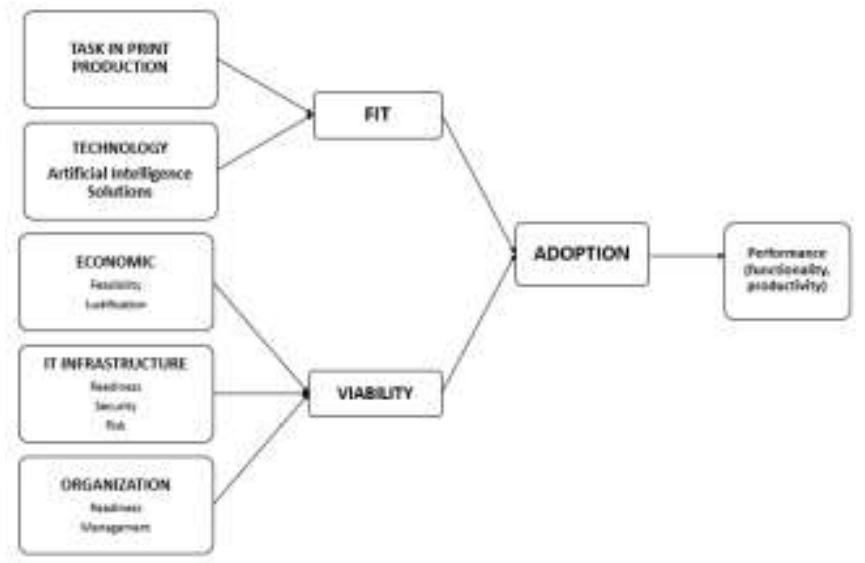

Fig. 2. A framework for adopting Artificial Intelligence for Management Information Systems (Adapted from Tjan, 2001)

\subsection{Methodology}

The context of Al is an emerging concept, and due to the exploratory nature of this research, the appropriate choice of methodology to test the proposed framework (Figure 2) is a qualitative multi-case study in conjunction with qualitative research methods. To add to the robustness of the study, this research will explore how Al solutions can be implemented successfully in a diverse group of printing industry segments.

Due to the complexity of defining the printing industry, in this research, the classification of the printing industry in Malaysia is adopted from The Malaysia Standard Industrial Classification 2008 (MSIC 2008) Version 1.0, as prepared by the Department of Statistics, Malaysia, which offers a standard classification of productive economic activities. This classification is adopted because its main purpose is to provide a set of activity categories according to which statistics can be collected and presented and through which entities can be classified according to their economic activities. Furthermore, MSIC 2008 Version 1.0 conforms closely to the International Standard Industrial Classification of All Economic Activities (ISIC) Revision 4, published by the United Nations Statistics Division, with some modifications to suit national requirements. This information applies directly to the print manufacturing industry and lists all activities relevant to it.

We propose conducting interviews with key figures in the field to explore and validate the Al solutions definitions and their components. Experts will include those from companies with known Al implementations. Data will be collected by employing a variety of techniques, including in-depth, open-ended, unstructured interviews with key experts from the respective groups of different key stakeholders in Al implementation projects in the chosen printing segments. These key contributors will include Chief Officers and leaders in printing departments. 
A systematic interview protocol suggested by Yin (2015) will be adopted to strengthen the reliability of the data collection. Prior to the interviews, face validity (Patton, 1997) will be performed by analysing the data collection plans with respect to the content of the data and the procedures to be followed.

\subsection{Discussion and Conclusion}

The purpose of this ongoing research is to conceptualize a framework to investigate Al solutions implementations in the printing industry. We recognize that $\mathrm{Al}$ is an enabling technology for Industry 4.0, and in order to support government initiatives to enhance productivity in the manufacturing sector, particularly in the printing industry, we feel it is necessary and critical to look at the organisational and task/technology characteristics of today's global business environment. As with any other IS implementations, Al solutions implementations comprise technology as well as human involvement. Under these circumstances, it is important to investigate the impacts of task characteristics, technology characteristics, economics, and IT infrastructure factors on the organisational decisionmaking process. Thus, in this research, the importance of studying systems' viability and fit prior to adoption is stressed. Therefore, the proposition of this study is to perform the required tasks-to-technology needs analysis to determine a good fit for the required tasks. In addition, viability and fit should have positive effects on the organisation's performance, which can be measured by functionalities and productivity.

Based on this conceptual paper, we plan to pursue a commercial printing company in Malaysia. In order to overcome the great challenges of production planning and management, brought about by their intrinsic, highly volatile demand stream (Zeng et al., 2013), we aim to test the feasibility of our proposed framework in order to remain relevant and competitive within the increasingly complex printing industry. Based on the fact that Al solutions are embedded within the ES, we hope that by looking to commercial printers this study will serve to provide us with insightful data and key results that will, in turn, serve to provide the necessary empirical evidence to support the proposed framework and aid the industry in general in its pursuit of Al technology paths. We further hope that the use of a multiple-case-studies approach to examining the success or failure of Al solutions adoption and implementation will lead to major implications, notably the enhancement of the interoperability of equipment or systems that could support local and global Industry 4.0 technologies and processes. The findings are expected to enable the manufacturing sector to move into Industry 4.0 and, along the way, contribute to fulfilling Malaysia's commitment to the United Nation's Sustainable Development Goals (SDGs), namely Goal \#9 (Industry, Innovation And Infrastructure) and Goal \#12 (Responsible Consumption and Production).

\section{Acknowledgments}

Special acknowledgement to the Faculty of Art \& Design, Universiti Teknologi MARA (UITM).

\section{References}

Awa, H. O., Ukoha, O., \& Emecheta, B. C. (2016). Using T-O-E theoretical framework to study the adoption of ERP solution. Cogent Business and Management, 3(1), 123. https://doi.org/10.1080/23311975.2016.1196571

Bodrow, W. (2017). Impact of Industry 4.0 in service-oriented firm. Advances in Manufacturing, (November). https://doi.org/10.1007/s40436-017-0196-3

Ding, Y., \& Qu, W. G. (2014). a Multi-Level Model of Enterprise Systems Adoption. Proceedings - Pacific Asia Conference on Information Systems, PACIS $2014,2019$. https://doi.org/10.2147/RRCC.S43364

Hultén, P., Viström, M., \& Mejtoft, T. (2009). New printing technology and pricing. Industrial Marketing Management, 38(3), $253-262$. https://doi.org/10.1016/j.indmarman.2008.01.001

Kipphan, H. (Ed.). (2001). Handbook of Print Media. https://doi.org/10.1007/978-3-540-29900-4

Li, B., Hou, B., Yu, W., Lu, X., \& Yang, C. (2017). Applications of artificial intelligence in intelligent manufacturing: a review. Frontiers of Information Technology \& Electronic Engineering, 18(1), 86-96. https://doi.org/10.1631/fitee.1601885

Liang, T. P., Huang, C. W., Yeh, Y. H., \& Lin, B. (2007). Adoption of mobile technology in business: A fit-viability model. Industrial Management and Data Systems, 107(8), 1154-1169. https://doi.org/10.1108/02635570710822796

Masod, M. Y. Bin. (2018). Reinventing Printing Business towards Industry 4.0. Journal of Printing Science and Technology, 55(6), 566-569.

Melnikov, A. V., \& Semenyuk, E. P. (2014). The information revolution and the modern printing industry. Scientific and Technical Information Processing, 41(1), 1-11. https://doi.org/10.3103/S0147688214010031

Miller, K. D. (1992). A Framework for Integrated Risk Management in International Business. Journal of International Business Studies, $23(2), 311-331$. https://doi.org/10.1057/palgrave.jibs.8490270

O'Donnell, J., \& Jackson, M. (2007). Solutions drawn from Australian case studies in mobile commerce. Conference Proceedings - 6th International Conference on the Management of Mobile Business, ICMB 2007. https://doi.org/10.1109/ICMB.2007.59 
Petr, S. (2018). Towards Autonomous Al Systems for Resource Management: Applications in Industry and Lessons Learned. In Lecture Notes in Computer Science (including subseries Lecture Notes in Artificial Intelligence and Lecture Notes in Bioinformatics) (pp. 12-25). https://doi.org/10.1007/978-3-319-94580-4_2

Poon, P., \& Wagner, C. (2001). Critical success factors revisited: Success and failure cases of information systems for senior executives. Decision Support Systems 30(4), 393-418. https://doi.org/10.1016/S0167-9236(00)00069-5

Schwab, K. (2016). The Fourth Industrial Revolution. World Economic Forum, 199. https://doi.org/10.1017/CBO9781107415324.004

Soja, P., \& Paliwoda-Pȩkosz, G. (2009). What are real problems in enterprise system adoption? Industrial Management and Data Systems, 109(5), 610-627. https://doi.org/10.1108/02635570910957614

Willy, A. M. (2018). Malaysian print media business model a dying breed in digital age, says HLIB Research. Retrieved April 24, 2019, from The Edge Markets website: https://www.theedgemarkets.com/article/malaysian-print-media-business-model-dying-breed-digital-age-says-hlib-research

Xu, Z., Brown, D., \& Stevenson, M. (2017). ES Adoption in Chinese SMEs: Policy Effects on Users and Providers. AMCIS 2017 - America's Conference on Information Systems: A Tr Adition of Innovation, 2017, 1-23.

Zeng, J., Jackson, S., Lin, I.-J., Gustafson, M., Hoarau, E., \& Mitchell, R. (2013). Operations simulation of on-demand digital print. IEEE Conference Anthology, 1-5. https://doi.org/10.1109/ANTHOLOGY.2013.6784976 